motors mounted on a steel frame furnished with springs to deaden the vibration. Each propeller is driven by its own motor, but, in case of need, one single motor can drive the two propellers at the same time. The gear for the reduction of speed is placed in the prolongation of the driving shaft, beyond the propeller. The two propellers, of polished wood, have a diameter of 19 feet 8 inches, and are placed laterally in front, one on each side of the car, projecting beyond the sides of the steel framework. They occupy a position midway between the car and the balloon. The tractive power of each propeller is ascertainable at any moment. The dirigible is built to be able to ascend to an altitude of 6560 feet, and it is capable of travelling about 750 miles without replenishing its supplies of gas and fuel.

The Clement-Bayard No. 2 left Lamotte-Breuil with a crew of seven people, including $\mathrm{M}$. Clément, the designer of the vessel, on October I6 at 7.5 a.m. (G.M.T.), passed over Amiens at 8.29 and Boulogne at I0.15. The Channel was crossed in some fifty-five minutes, and Ashford seen at 11.45 a.m. Tonbridge was passed at 12.29 p.m., the Tower Bridge at I.4, and Wormwood Scrubbs was reached at $\mathbf{1 . 2 5}$. The whole distance, of nearly 260 miles, was thus covered in a little more than six hours at an average speed of about 43 miles an hour. The greatest altitude attained during the flight was between 800 feet and 900 feet, but most of the travelling was done between 600 feet and 700 feet. 'The average temperature was $60^{\circ} \mathrm{F}$. The success of the enterprise must be attributed largely to the very favourable weather conditions which prevailed during the flight. There was only a slight wind, and it was in a direction which assisted the movement of the airship, so that the demand made upon the power of independent navigability was not great. We still await the construction of an airship which will satisfy the War Office tests, one of which is that the vessel has to traverse a triangular course of 300 miles within a fixed time-limit. When this has been done it will be possible to form a satisfactory estimate of the advantages of power-driven airships over the ordinary spherical balloon.

The America, in which $\mathrm{Mr}$. Wellman with five companions made the daring attempt to cross the Atlantic, is a dirigible of the frameless type; it is 228 feet long, its greatest diameter $5^{2}$ feet, and it has a volume of 345,000 cubic feet. According to the Daily Telegraph (under the auspices of which, with the New York Times and other American papers the flight was undertaken), the balloon is composed of three thicknesses of cotton and silk gummed together with rubber to make it gastight, and weighs $4850 \mathrm{lb}$. Underneath the balloon is suspended by steel cables the car, weighing $4400 \mathrm{lb}$. This car is built of the highest grade steel tubing, and in places withstands stresses of twelve tons. It is 156 feet in length, and the steel tank at its base is 75 feet long, with a capacity of 1250 gallons of gasoline. The engines, three in number (two of 80 horse-power and a service motor of ten horse-power), are placed in the steel car. Each of the large motors drives a pair of twin screws, and each propulsion system is independent of the other. The motors and other machinery weigh about $1_{500} \mathrm{Ib}$. An electric light system, a wireless telegraph equipment, and a telephone connecting the different parts of the ship were installed.

Hanging from the airship by a steel cable is the equilibrator, a part of which floated upon the sea, the other being suspended vertically in the air. The purpose of this is to act as an automatic regulator of the upward and downward movements of the airship. When the ship rises it must lift some of the equilibrator from the sea in order to go up, and this added weight checks the rising movement. Conversely, when change of temperature or accumulation of moisture caused the airship to descend, a greater part of the equilibrator was?let down upon the sea, thus reducing the weight carried by the balloon and checking the descent.

The total supply of gasoline carried was in,00o lb., or about I80o gallons, which was considered sufficient to drive the airship from Atlantic City to Europe. The distance is about 3000 miles. With one engine running the airship could make a speed of 20 miles per hour, and the quantity of gasoline carried would run one engine 200 NO. 2 I 38 , VOL. 84$]$ hours. With both engines running the ship's speed in still air could be about 26 miles per hour.

After leaving Atlantic City at 8.5 a.m. on Saturday morning, October 15 , the America travelled 20 miles in the first hour, but later the rate was reduced to 15 miles an hour. Nantucket Island, which is about 300 miles from the starting place, was reached in twenty-four hours. A wireless message was received from $\mathrm{Mr}$. Wellman at x 2.45 p.m. on Sunday, October 16, when the airship passed out of range of communication with Nantucket Island. The vessel was then directed to the north-east, and early on the morning of October 17 was believed to be travelling between Nantucket Island and Nova Scotia. At 4.30 on October I 8 the airship was sighted in distress by the Royal Mail Steam Packet Company's steamer Trent, and after some difficulty Mr. Wellman and his crew were rescued and taken on board, the airship being abandoned. The position in which this occurred was latitude $35^{\circ} 43^{\prime} \mathrm{N}$. and longitude $68^{\circ} 18^{\prime} \mathrm{W}$., which is nearly 400 miles east of Cape Hatteras, on the North Carolina coast. The total distance covered by the airship appears to have been about 900 miles, and the duration of the voyage, during which she was in the air continuously, was sixty-nine hours.

\section{MATHEMATICS AND PHYSICS AT THE BRITISH ASSOCIATION}

THE address of the president of Section A, Prof. E. W. Hobson, was read on Thursday, September. I ; this has appeared in full in these columns (NATURE, September I, p. 284). It was succeeded by a paper-probably the most important paper read at the meeting-by Sir J. J. Thomson on positive rays. By the use of very large vacuum tubes Sir Joseph has been able to investigate the discharge at higher vacua than hitherto. Specially studying the rays which pass through a hole in the kathode, he detects :-(r) Rays undeviated by magnetic or electric forces. (2) Secondary positive rays, produced by these, which are deflectable by both forces, have a constant velocity of about $2 \times 10^{8} \mathrm{~cm} . / \mathrm{sec}$, at all pressures and potential differences. The value of $\mathrm{e} / \mathrm{m}$ for these is $\mathrm{IO}^{4}$. They are accompanied by negatively charged ones similar in every respect to the positive ones, except in respect to charge. (3) Rays characteristic of the gases in the tube, conspicuous only when the pressure is low. Their velocity varies with the potential difference. When several gases. are present, the maximum kinetic energy of the rays from each gas appears to be the same and equal to that due to a fall through the potential difference between the negative glow and the kathode. The value of $e / m$ is inversely proportional to the atomic weight of the gas. They are probably atoms carrying unit positive charge; in the case of hydrogen there are rays corresponding to the molecule as well. Some of these have negatively charged rays associated with them. In a magnetic field the rays from a mixture of gases spread out into a sort of spectrum. With carbon monoxide two bands are formed, one due to carbon, the other to oxygen. As exceedingly small quantities of gas may be dealt with in this way, it appears probable that interesting results may follow from the application of this method to the analysis of gases in vacuum tubes. (4) Retrograde rays, travelling: from the kathode in the same direction as the kathode rays. These are of types (I) and (2). They have negativeconstituents.

Dr. R. A. Houston followed with an exhibition of a spectrophotometer of the Hüfner type, which he has: previously described in the Phil. Mag. for February, 1908, and with a description of a new and simple means of producing interference bands. An approximately rightangled prism is placed in front of a slit; the two emergent beams produce interference bands in front of the prism. This is being used as a student's exercise; it does not appear, however, that the bands can be put to any practical use. A new gyroscopic apparatus was next exhibited by Prof. A. E. H. Love. The machine consists essentially of a pair of bicycle wheels fixed to a round steel bar as an axle. The bar is prolonged beyond one wheel to carry a wooden wheel, by means of which it can be set 
spinning, and the other wheel carries a square tin plate on which is fixed a card coloured in squares. The machine is so mounted that it can turn freely about its centre of gravity. To throw it out of truth without disturbing the centre of gravity two small bolts are inserted in the rims, one in each, at opposite points. The machine is set spinning about the axis of the wheels. When the instantaneous axis cuts the card at a point well within a square, a patch of the colour of that square is seen distinctly, and the rest of the card appears confused. As the axis moves, a series of distinct patches are seen at short intervals.

On Friday, September 2, the section divided. In the mathematical department Major P. A. MacMahon opened the proceedings by reading a paper on functions derived from complete and incomplete lattices in two dimensions, and the derivation therefrom of functions which enumerate the two-dimensional partition of numbers. The investigation was suggested by the solution of a ballot problem of finding the chance that at every stage of the voting the candidates are in their final order.

Dr. Baker in his paper on a certain permutation group said that he had been led to inquire into its properties by becoming interested in a game played by some children. The game consisted in writing down a series of letters and then rearranging them by writing the last first, the first second, the last but one third, the second fourth, and so on. When the rearrangement was completed if was performed again, and so on repeatediy. Finally, it was found that, after a certain number of rearrangements, the original order of the letters was obtained.

For instance, the set of seven letters

gives

$$
\begin{array}{lllllll}
a & b & c & d & e & f & y
\end{array}
$$

$\begin{array}{lllllll}g & a & f & b & e & c & d \\ d & g & c & a & e & f & b \\ b & d & f & g & e & c & a \\ a & b & c & d & e & f & g\end{array}$

Dr. Baker showed that when there are $n$ letters the number of rearrangements required to reobtain the original order is the least number $r$, such that one of the two numbers $2^{r}-\mathrm{I}, 2^{r}+\mathrm{I}$, is divisible by $2 n+\mathrm{I}$.

Dr. Baker also read a paper on the trisection of elliptic functions, in which the problem was discussed in connection with the theory of the quartic equation.

Lieut.-Colonel Allan Cunningham read two notes of great interest on the theory of numbers, one on the factorisation of $\left(2^{77}+1\right)$, and the second on the question whether $\left(2^{p}-2\right)$ is divisible by $p^{2}$ ( $p$ a prime). Upon these Dr. Baker made the following remarks:-

We are often told that the problems of the physicist are set to him by nature itself, but the problems of the mathematician are invented by himself, and therefore worthy of less attention. Those to whom this seems a sound criticism will probably admit that the puzzling problems of integral numbers are put to us from without We should therefore regard the theory of numbers with especial concern, quite apart from its own extraordinary interest. In Germany at the present time great progress is being made in the subject; it touches our reputation as English-speaking mathematicians to encourage, so far as we can, a similar interest in the theory of numbers here.

Prof. A. W. Conway read a paper on the convergence of a certain series used in electron theory. The series was one obtained by means of Lagrange's expansion.

Dr. J. W. Nicholson read a paper on some problems of initial motion of electrified spheres, in which he referred to the work of G. W. Walker and Prof. Conway. Starting with an electron having a small Newtonian mass, it was shown that difficulties are met with when this mass is reduced to zero; it appears impossible to ascribe an initial acceleration to a conducting sphere without introducing imperfection in the conductivity, although the electrical distribution on the sphere tends to become uniform very rapidly. These results have a bearing on a possible conception of the electron. These difficulties are absent from the corresponding problem for an insulating sphere.

Dr. Duncan M. Y. Somerville pointed out the need of a non-Euclidean bibliography. It is now thirty years ago since Halsted published the first bibliography of nonNO. 2 I 38 , VOL. 84$]$
Euclidean geometry, and one still finds it referred to as a standard work. In the discussion Prof. Love suggested that a report on the subject would be more valuable. (The general committee has since appointed a small committee to consider this question and draw up a report if considered advisable.)

Mr. H. Bateman read a paper on the present state of the theory of integral equations, in which he sketched the history of the subject and indicated some of the physical applications. Prof. Conway and Prof. Webster remarked that in the problems they had tried it was very difficult to get a simple solution by means of integral equations. In answer to this, Dr. Hobson pointed out that in the problems referred to the theory of integral equations fails to give a simple solution because a simple form of the solution does not exist; but by studying the theory we can hope to obtain some idea of the form and behaviour of the solution, although the analytical expression for it is not suitable for calculation. This important, exhaustive report of Mr. Bateman's has been ordered to be printed in extenso.

Mr. Bateman also read a paper on the foci of a circle in space and some geometrical theorems connected therewith. Special attention was paid to twisted polygons formed of isotropic lines.

Prof. J. C. Fields read a paper on the theory o! ideals. Starting from Hensel's power-series, he defined adjointness relative to a prime $p$ in a manner analogous to that in which he has defined the property in connection with the algebraic functions. If $\epsilon$ is the solution of an algebraic equation, it was shown that we can construct a rational function $R(\epsilon)$ possessing any assigned set of adjoint orders of coincidence corresponding to a prime $p$. It is deduced that we can construct a general function $R(\epsilon)$ which represents only integral algebraic numbers, and possesses a single coincidence with the branches of an assigned one of the cycles corresponding to any prime, while it is not conditioned with regard to any other specific prime or any other cycle corresponding to the prime in question. The aggregate of numbers so represented is a prime ideal.

The report of the committee on the further tabulation of Bessel functions was taken as read. This committee is proceeding to calculate the functions $\mathrm{I}_{1}(x)$ and $\mathrm{K}_{n}(x)$. Its scope has been extended so as to empower it to proceed to the calculation of any necessary functions.

Meanwhile, a joint meeting of the physics department and Section $B$ (Chemistry) was being held. The proceedings of this meeting will be in part reported by the chemical section. Two papers only will be dealt with here. A paper was read by Mr. J. A. Crowther on the number of electrons in the atom. From the mean scattering of $\beta$ particles in passing through a substance, it is deduced that the number in question is three times the atomic weight, provided that the positive electricity in the atom has a volume comparable with the atom itself. The substances considered are carbon, aluminium, copper, silver, and platinum. The numbers obtained, if the positive electricity be assumed to be divided into small particles comparable in size with the negative, are not proportional to the atomic weight-a result which would be in conflict with experiments on the scattering of Röntgen rays-and it is thence concluded that this alternative hypothesis is not correct.

The second paper was by Dr. R. D. Kleeman, on the attractive constant of a molecule of a compound and its chemical properties. Making use of previous deductions from surface tension and latent heat data, Dr. Kleeman shows that the various chemical compounds can be divided into groups, and it is found that this grouping corresponds with that obtained from purely chemical considerations; for example, the amines fall into three groups. The property specially studied is the ratio $\mathrm{T}_{c} / \Sigma \sqrt{ }(\mathrm{A})$, where $\mathrm{T}_{c}$ is the critical temperature and the denominator is the sum of the square roots of the atomic weights of the components of the compound.

The proceedings on Monday, September 5, began with a demonstration by Dr. H. J. S. Sand of vacuum-tight seals between iron and glass. An iron wire is sealed into a glass tube. While the glass is hot a small piece of heated steel tube surrounding the wire is pushed a few millimetres into the glass. After cooling, the tube is 
soldered to the wire. The vacuum-tight seal is produced between the inner surface of the elastic steel tube, which on cooling is put under tension, and the glass, which comes under compression. Seals with wires of I $\mathrm{mm}$. diameter have been produced in this way.

Dr. T. H. Havelock followed with deductions from the relations between densities and refractive indices. Dr. A. G. Webster (of Worcester, Massachusetts) gave a detailed account of a complete apparatus for the measurement of sound. The producer of the sound was a steel diaphragm rigidly driven by an electrically maintained cuning-fork, and made the back of a resonator of the form of a small hollow chamber or of a tube of variable length. The reaction of the sound upon the amplitude of the fork enables the constants of the resonator to be accurately determined, so that the rate of emission may be measured in watts. The phonometer (or measurer of the sound) is a glass diaphragm, made the base of a resonator, and bearing a light mirror, which constitutes one mirror of a Michelson interferometer. The displacement is measured stroboscopically by a telescope, and the amplitude of the pressure change is read off on a scale in dynes $/ \mathrm{cm} .{ }^{2}$. The instrument is as sensitive as the ear for a pitch of 256 vibrations per second, and an accuracy within o per cent. is claimed.

In the short discussion aroused by this paper some doubt seemed to be felt of the agreement of results given with those obtained by Lord Rayleigh, but in the absence of trustworthy memories the point was left unsettled. Questioned as to the power exerted while he himself had been speaking, Prof. Webster left it to be inferred from the statement that ten million cornets (each of which could be heard half a mile away) emitted at the rate of a horse-power.

Prof. W. M. Hicks followed with a paper on the relation of spectra to the periodic series of the elements. In this he described some results recently obtained by him in a critical study of the spectral series of the second and third groups of the periodic table of elements, more especially their dependence upon the atomic volume of the element. Values for atomic volume or of density very close to observational values can be deduced in the case of the first three groups of the periodic series. Applying the method to the spectrum of europium as given by Exner and Hashek, a density of $\mathrm{r} 3 \cdot \mathrm{r}$ was predicted for that element. Sir Norman Lockyer, discussing the paper, emphasised the importance of a study of series, especially in regard to the stars. In a paper on the series spectrum of the mercury arc, Dr. S. R. Milner gave the results of a photographic study of the mercury arc in racuio, thus avoiding the faint continuous background which fogs the plate when the arc is observed in air; very much longer exposures can for this reason be given, and many new lines are then observed, among which the lines forming the continuation of the various series of mercury were strikingly developed. Measurements have been made up to the fifteenth line in the diffuse series and the thirteenth of the sharp series. Rydberg's difference law is exactly satisfied.

Mr. A. E. Oxley described an apparatus for a production of circularly pularised light obviating the lateral displacement of the beam produced by Fresnel's rhomb, but possessing the advantages of this rhomb in other respects. Two similar rhombs of glass are placed end to end in contact so as to form a bent double rhomb. By suitably choosing the dimensions the required object is attained. The angle of the rhomb chosen is $74^{\circ} 38 \cdot 2^{\prime}$ for glass of index $\mathrm{I} \cdot 5035$. The length $\left(\mathrm{I}_{5} \mathrm{~cm}\right.$.) is, however inconveniently long. A much shorter form, in which three reflections of the light occur, is obtained by putting in close contact two trapezium-sectioned prisms, the faces in contact being those containing the shorter of the two parallel edges of the trapezium. The relative retardation can be made $2 \pi+\pi / 2$, and the emergent light will then be circularly polarised. The apparatus can advantageously replace a quarter-wave plate in the quantitative study of elliptic vibrations. Mr. Oxley also described a new halfshade analyser, consisting of a double rhomb of glass of suitable angle to produce a retardation of $3 \pi$, which is equivalent to $-\pi$

Section G (Engineering) then joined to participate in a discussion on the principles of mechanical flight; opened NO. 2 I 38 , VOL. 84$]$ by Prof. G. H. Bryan. This discussion wandered away from the title, and developed into one on the relative positions of the mathematician and the practical engineer in the origination and development of new ideas on the subject of aviation. The engineers were present in strength, and the evidence brought forward from the parallel case of motion on water seemed to be greatly in their favour. Of the points more particularly bearing upon the advertised title of the discussion we may mention Mr. Dugald Clerk's advocacy of much lighter engines and of a considerable modification of the usual thermodynamic cycle. He recommended differences of pressure of two to one instead of five or more to one as at present. Mr. Scoble's account of his propeller tests was also of much value.

The proceedings of Tuesday, September 6, were opened with a discussion on atmospheric electricity, initiated by Dr. Charles Chree. He explained that atmospheric electricity includes a great variety of phenomena. Omittin aurora as a subject so large as to require a separate discussion, there are the questions of the potential gradient in the atmosphere, the influence of potential gradient and electrical charges on the growth of vegetation, the phenomena of thunderstorms, the loss the charge experienced by insulated bodies, the number and nature of the positive and negative ions in the air, the vertical earth-air currents, and the phenomena of radio-activity. The potential gradient and its diurnal and annual variation have been the subject of study for a good many years, and we know that the phenomena vary largely with the season of the year at any given station, and that there are notable differences between different stations at ground-level. As yet but little is known of the diurnal and annual changes at different heights in the free atmosphere. Observations made near the top of the Eiffel Tower suggest that the phenomena alter rapidly as the height above the ground increases. Thus observations from balloons and kites, if these could be maintained at a fixed level, would be of great importance. The influence of electricity on the growth of plants, first seriously studied by Prof. Lemström, seems not unlikely to prove in the future to be of economic importance. The phenomena of thunderstorms have received considerable attention from meteorologists, but many lines of investigation present themselves. The loss of charge of insulated bodies and the ionic charges in the atmosphere have been studied most in Austria and Germany-Elster and Geitel, in particular, having done much pioneer work. In this country Mr. C. T. R. Wilson has investigated the electric charge brought down by rain, and has invented an instrument for measuring the earth-air current. While a great number of theories have been advanced to account for the several phenomena, there are few, if any, of them which command anything like universal acceptance.

Sir Oliver Lodge referred to the existence of a positive gradient of potential during fine weather and a negative gradient during wet weather, and spoke of the possibility of influencing the weather by varying the potential gradient, and thought that rain might be produced in this way, and that here was a field of experiment for the enterprising capitalist. Referring to the effect of electricity on plant life, he explained that the experiments with which he had been connected showed that in dull weather the plants were stimulated by the electricity, and the effect was good, but in bright, sunny weather they were overstimulated, with consequent bad results. He did not think that the action on plants was due to nitrification, but to some effect on the growing tips.

Dr. Shaw pointed out that in order to produce rain in considerable quantities it would be necessary to find a source for an enormous amount of energy, and he urged that any attempt to reverse the electric field should be first of all thoroughly worked out in the laboratory. He asked whether fine weather electricity had anything to do with thunderstorms. The two phenomena seemed to be distinct from one another.

Sir J. J. Thomson thought the real difficulty about producing rain by electrical methods would be political. If one's efforts resulted in deluging neighbouring countries with rain they did not want, or in depriving them of their normal supply, difficulties would begin. As he understond Sir Oliver Lodge, it was not a question of supplying 
energy, but of transforming energy already existent in the atmosphere in order to produce rain. He referred also to the difficulty of explaining the return to earth of the outward flowing negative electricity, and mentioned, in conclusion, the relation between the radio-active contents of the air and its previous history; air which had travelled over the sea was much less radio-active than that which had been for some time over the land.

Dr. Chree in his reply emphasised the fact that during rainfalls there are fluctuations of potential, and in conclusion urged the necessity of observations over much wider areas before many of the problems of atmospheric electricity could be settled.

At this stage the section divided. In the department of cosmical physics Dr. W. Schmidt, of Vienna, communicated an interesting description of a new instrument, the variograph, designed by him for measuring short waves in atmospheric pressure. He showed records obtained by it at Innsbruck and Vienna. Conditions at Innsbruck, especially in the winter months, are very favourable for the production of waves, the cold air in the valley lying beneath a warmer upper layer. By recording with two instruments $2 \mathrm{~km}$. apart, Dr. Schmidt deduced that both progressive and standing waves occurred, the period of the latter being considerably greater than that of the former; in a particular case the periods were 3.5 minutes and 9 minutes respectively, and the record showed the interference of the two sets of waves. Dr. Schmidt showed, too, that in Föhn weather, when regular waves were recorded, the regularity ceased when the Föhn wind actually broke through the cold layer and blew at Innsbruck, proving that the layer of discontinuity was essential to the formation of the waves. In some cases regular waves preceded by several hours the occurrence of line-squalls, corroborating Russell's observations of cirrus clouds.

Mr. Dines spoke on the records from the upper atmosphere obtained during the passage of the earth through the tail of Halley's comet. The traces obtained by Mr. Dines in ordinary cases are of two kinds, one in which the up and down curves coincide, the other in which loops are formed. The traces at the time of the comet showed an abnormally large proportion of the second kind, but it was not possible to say if the peculiarity was due to the comet or to the type of the prevailing weather.

Dr. Nicholson in a paper on radiation pressure in cosmical problems showed that more extended calculations do not confirm Schwarzschild's results in detail, but the general character of these results is preserved.

Miss Margaret White showed a series of slides giving the results of the hourly balloon ascents made from Manchester in March. The results corroborated in their main features those obtained in June, I909, and communicated at the Winnipeg meeting.

Mr. Stupart gave some results of an inquiry into the vertical temperature gradients in Canada in the winter months. The principal conclusions were:-(I) that in cold winters in Manitoba the temperature increased upwards, the mountains being warmer than the plains (2) that in warm winters the mountains were colder than the plains, and the vertical gradient approached the adiabatic value.

Mr. Gold communicated the results of an investigation into the effect of radiation on $H \ldots$ the height, and $T_{c}$ the temperature of the advective region. So far as radiation is concerned, the variation both in the temperature and in the absolute humidity of the atmosphere tend to increase the value of $\mathrm{H}_{c}$ with approach towards the equator, but their effects on $\mathrm{T}$, are in opposite directions. A necessary condition for the existing state of affairs is that the atmosphere should be very nearly transparent to low temperature radiation for considerable regions in the spectrum.

Prof. F. G. Baily described a sensitive bifilar seismograph for recording undulatory movements of the earth's surface of short period. By a system of multiplying levers, great sensibility is attained, and it may be expected that, when the present experimental instrument is replaced by a final form exposed in a suitable chamber, valuable results will be obtained.

In the department of general physics, which sat simultaneously with the above, Mr. Twyman described, on NO. 2 I 38 , VOL. 84$]$ behalf of Prof. C. Féry, a successful attempt to simplify the long-range spectrograph to make it suitable for industrial investigations concerning metals, alloys, \&c. The principle of auto-collimation is employed, a $30^{\circ}$ quartz prism being traversed twice by the beam of light. By giving suitable curvatures to the two sides of the prism it acts also as the lens-system, producing a sharp spectrum on a cylindrical surface, exactly as with a curved reflecting grating, and with a much less inclination of the plate.

In a paper on the magnetic field produced by the motion of a charged condenser through space, Mr. W. F. G. Swann discussed the possibility of detecting the presumed field by means of a rotating coil, even though the impossibility of detecting it by a magnetic needle is admitted. His analysis seemed to indicate that if the specific inductive capacity may be looked upon as a quantity absolutely continuous throughout the dielectric, a magnetic flux through the coil should exist, but that if the dielectric action is to be explained by electric charges or doublets, no resultant magnetic flux is to be anticipated. Experiments made by the author gave a null effect, and this is taken to support the doublet theory of dielectric action.

Three papers were read by Prof. J. C. McLennan on behalf of the authors, who are his students at Toronto. In the first Mr. V. E. Pound details the results of experiments on the secondary radiation from carbon at low temperatures when bombarded by the $\alpha$ rays from polonium. Fifty per cent. more is produced at the temperature of liquid air than at atmospheric temperature. This is attributed to the much larger amount of air occluded in the carbon. The second paper, by Prof. McLennan and Mr. N. Macallum, was on a resolution of the spectral lines of mercury by a high-grade echelon spectroscope made by Messrs. A. Hilger. A number of slides were exhibited showing the components of the green and blue mercury lines and their resolution under the action of a magnetic field. The third paper was by Mr. W. T. Kennedy, on the active deposit obtained when the emanation from actinium is allowed to diffuse freely between two parallel plates placed about 2 millimetres apart over the actinium salt, the plates being maintained at a difference of potential of 250 volts. The deposit is found to reach a maximum for a particular gas-pressure. It was concluded that the proportionate amount of emanation which possesses a positive charge varies with the pressure.

Dr. H. S. Allen followed with an important summary of our present knowledge of photoelectric fatigue. This was accompanied with a bibliography, which has been ordered to be printed in extenso. This was succeeded by an interesting paper by Drs. W. Makower and S. Russ and $\mathrm{Mr}$. E. J. Evans on the recoil of radium $B$ from radium $A$. The magnitude of the effect observed was of the order to be expected if radium $B$ carries the atomic charge of electricity and if its atomic weight is 214 , as is to be expected on the transformation theory of radio-active processes.

The proceedings on Wednesday, September 7 , began with a very interesting account by Sir Norman Lockyer of his work on stars and their temperatures. The spectra of the hottest stars indicate that in them we have to deal simply with hydrogen and with another form of hydrogen produced from it: but helium runs hydrogen very close as one of the constituents of a star's earliest atmosphere. Iron, even in a proto-form, enters into a star's atmosphere at a much later stage, and iron such as we know it in our laboratories at a later stage still. The general conclusion from Sir Norman's work is that we are able to establish a palæontology of chemical substances.

Prof. W. M. Hicks sketched some of the evolutions of a vortex, and was succeeded by Dr. C. Chree, who read a critical paper on the rate of propagation of magnetic disturbances. Dr. Bauer, of the Carnegie Institution, believes he has established as a fact that the so-called "sudden commencements" of magnetic storms are propagated at such a rate as to take, on an average, about $3 \frac{3}{4}$ minutes to go round the earth, and he believes that the cause of these disturbances is a peculiar form of overhead electric current in the plane of the earth's equator due to charged ions, the height of which, on the average, is about fifty miles. Dr. Chree considers that the theory 
which Dr. Bauer has advanced to account for the motion of these charged ions is unsatisfactory in several respects, and he further considers that the experimental evidence which has been brought forward by Mr. Faris to support Dr. Bauer's theory is inconclusive.

Then followed several reports of committees, which were either outlined or taken as read. These included the report of the seismological committee, in which reference is made to the interesting results on the semi-diurnal change in level (caused by the tide) obtained by Plummer at Bidston Observatory. The meeting of the section then came to an end.

\section{CHEMISTRY AT THE BRITISH ASSOCIATION.}

I $N$ arranging the programme for the Sheffield meeting the organising sectional committee had made it the main object to discuss broader questions of interest to other sections rather than to encourage the reading of papers appealing mainly to specialists; further, in view of the special character of the industries of Sheffield, much of the programme was devoted to metallurgical subjects. The results of the meeting fully justified this departure, and the three joint discussions not only proved of the greatest interest, but were most stimulating in character; indeed, it is probable that in two cases, at least, they will serve as points of departure for much new research. The metallurgical papers were equally stimulating and in harmony with the tone set by the president's addressthe meeting as a whole should do much to inspire the filling of some of the gaps in our knowledge to which Mr. Stead made reference.

The joint discussion with Section A attracted a very large audience. The subject chosen-combustion-should have had the cooperation of the engineers, who were discussing the report of their committee on gaseous explosions on the same morning, but could not see their way to attend the joint meeting. Prof. Bone presented a report giving a very complete summary of the principal researches upon the chemical aspects of gaseous combustion during the past thirty years. He dealt in turn with ignition temperatures, the explosion wave, the pressures produced in gaseous explosions, the influence of moisture upon combustion, the combustion of hydrocarbons, and the influence of hot surfaces upon combustion. This last question is of considerable technical importance, hot surfaces accelerating dissociation, and probably also combustion, and hence playing a potent part in the development and concentration of the heat in gas-fired furnaces. The line of attack followed has been to determine the rates of combination of different gases with oxygen when the reacting mixtures are brought into contact with various solid surfaces at selected constant temperatures.

Sir J. J. Thomson directed attention to the fact that combustion was concerned, not only with atoms and molecules, but also with electrons, i.e. bodies of much smaller dimensions and moving with very high velocities. These may precede the explosion wave and prepare the way for it by ionising the gas. The motion of the ions can be stopped at once by means of a transverse magnetic field, and it would be of great interest to repeat Prof. Dixon's experiments on the photography of the explosive wave under such conditions.

It had been shown by the work of Townsend and others that in carefully dried gases the velocity of the negative electrons might be Ioo times as great as the velocity of the positive electrons. The amount of moisture required to reduce this velocity to its ordinary lower value was exceedingly small, and comparable with that required to initiate chemical change. It was not unlikely that the two phenomena were very closely related.

In reference to the influence of hot surfaces in promoting combustion, it was not improbable that the emission of charged particles from the surface was a factor of primary importance. Hot lime gave out an enormous stream of negative electrons; hot metals emitted an excess of positive electrons. These electrons might produce very important effects by uniting (perhaps selecNo. 2 I 38 , VOL. 84$]$ tively) with moisture, with the oxygen or with the inflammable constituent of the gaseous mixture. The action of surfaces might ultimately be found to depend on the fact that they formed a support for layers of electrified gas in which chemical changes proceeded with high velocity.

Sir Oliver Lodge referred to the fact that the velocity of sound was not a constant quantity. If a bullet were to travel with a velocity greater than that of sound the air would be shattered as if by an explosion. This result was in practice prevented by the compression, and consequent heating, of the air in front of the bullet, whereby the velocity of sound was momentarily raised to perhaps three times its ordinary value. Whilst hot surfaces promoted combustion, cool surfaces had an opposite effect; this was responsible for the production of vast quantities of soot and smoke, especially in firing steam boilers. The discovery of a surface which would promote combustion even at lower temperatures would be of very great value.

Prof. H. B. Dixon stated that the explosion of hydrogen and chlorine by light was of special interest, as it did not occur in the well-dried gas. Both Mellor and Chapman and Burgess had failed to find any evidence of ignition by light of a mixture of two substances-three kinds of molecules seemed to be necessary. But when once the explosion wave was started it proceeded independently of moisture, and, indeed, was actually most rapid in the dry gas; the explosion was then propagated by molecular collisions between pairs of molecules. It was not unlikely that invisible compression waves might travel a little in front of the visible flame, the particles being thereby raised to a higher temperature, but remaining uncombined until they collided with one another.

Prof. Armstrong denied the possibility of any interaction taking place between two substances if neither was an electrolyte. Highly purified materials must be used for work of this kind. Perhaps the most suggestive experiment was that of Sir James Dewar, who had purified helium so perfectly by the use of charcoal cooled in liquid air that it would not permit an electric discharge to pass through it, although the presence of the gas was clearly shown by the radiometer.

A paper on the molecular weight of radium emanation by Sir Wm. Ramsay and Dr. R. W. Gray, was delivered by Dr. Gray, who first described in detail the construction of the micro-balance used, and showed how the exact volume of emanation weighed was determined. The mean value of $22 \mathrm{I}$ was obtained for the molecular weight of the emanation, and the fact emphasised that the radium emanation was in every sense a true chemical element. Chemically it is absolutely inert, and the atomic weight shows that it falls into the argon series in the periodic table, filling the second vacant space below xenon. The name "niton" (shining) and the chemical symbol Nt was proposed for the emanation. Sir J. J. Thomson suggested that the name should be left to the Congress of Radiology at Brussels (see Nature, October 13).

The more purely physical papers read at the joint meeting are dealt with in the account of 'the proceedings of the physical section.

The report on solubility submitted by Dr. J. V. Eyre is the outcome of a systematic study of the literature; the material is classified chronologically and according to subject, and contains a brief statement of the main conclusions arrived at by the various authors.

The conjoint discussion on the biochemistry of respiration was of the greatest value in enabling workers on the subject, representing the three sciences concerned, to correlate their views. Mr. F. F. Blackman, who opened the proceedings, gave a very complete summary of the present position of the subject, dividing it into three sections:-(r) the nature of the chemical reaction (or complex of reactions) that constitutes respiration; $(2)$ the extent to which this reaction in the cell conforms to the laws of general chemistry; (3) the influence on the progress of the reaction of the peculiar medium (protoplasm) in which it takes place. A summary statement of respiration takes the form of the equation for the complete oxidation of glucose, but actually the process is most complicated. The existing theories as to the stages in 